\title{
Presagios de independencia politica en el Seminario y Colegio de San Nicolás Obispo en Valladolid
}

\section{María del Carmen Rovira Gaspar}

J osé Pérez Calama fue maestro de Miguel Hidalgo y Costilla en el Colegio de San Nicolás Obispo en Valladolid. Por ser Calama una pieza esencial en la llamada, por mí, "revolución intelectual", me permito dar algunos breves datos de su vida. filosofía y teología en la Universidad de Salamanca. Llegó a México en 1765 , acompañando al prelado Francisco Fabián y Fuero, quien fue años después obispo de Puebla. Calama se ordenó de sacerdote en 1768; fue nombrado rector del Seminario, gobernador del obispado y miembro del cabildo eclesiástico en Puebla. Más tarde pasó a la diócesis michoacana, donde alcanzó el grado de deán y de arcediano en el obispado de Michoacán y chantre de la catedral de Valladolid, actual Morelia.

Se distinguió por su cultura y su inquietud por renovar y enriquecer la educación de los jóvenes colegiales. El 5 de junio de 1784 en carta dirigida a los señores consiliarios del Seminario Tridentino, doctor don Vicente Antonio de los Ríos y doctor y maestro don Miguel José Moche, plantea la necesidad de educar a la juventud, y afirma: "la felicidad de la Iglesia y del Estado pende de la buena educación de la juventud"; asimismo, aconseja el establecimiento de una academia de bellas letras político-cristianas en el Seminario Tridentino. ${ }^{1}$

Es precisamente en estos años, 1784, cuando el joven Hidalgo presenta su Disertación en el concurso organizado por Calama, obteniendo con ella la

${ }^{1}$ Estas noticias están tomadas de la "Colección de documentos relativos al doctor José Pérez Calama”, Michoacán, 1776-1785, ff. 17-18. Localizados en el archivo del antiguo obispado de Michoacán, Museo Casa de Morelos, Morelia, Mich. Copias conservadas en la biblioteca de El Colegio de México, y en José Pérez Calama, Política christiana. Introd. de Ernesto de la Torre Villar. Morelia, Universidad Michoacana de San Nicolás de Hidalgo, Centro de Estudios sobre la Cultura Nicolaíta, 1993, p. 375. 
máxima distinción y el premio correspondiente. Anteriormente, en 1782, la obra de Calama Política christiana. Para toda clase de personas..., se había publicado en Guatemala en la Nueva Ciudad de la Asunción. En 1789 se le nombró obispo de Quito. Calama salió del puerto de Acapulco en 1790 para dirigirse a dicha ciudad.

Al parecer, a Calama no le agradó ni el ambiente ni la sede episcopal de Quito, ni el país. Le afectó e inquietó la situación de miseria que vivían los indígenas; esto y otros muchos problemas con su clero dieron lugar a que decidiera abandonar Ecuador y consecuentemente el obispado que ocupaba. Sin embargo, en su estancia en dicha capital, y obedeciendo a la inquietud que siempre tuvo por mejorar la cultura y la educación, procuró elevar la preparación de los sacerdotes quiteños, así como mejorar la educación que se impartía a los jóvenes seminaristas.

Calama renunció al obispado de Quito el 30 de noviembre de 1791, y se embarcó en Guayaquil con el fin de llegar a México y quizá más tarde a España. El barco en que regresaba naufragó; Pérez Calama perdió la vida. Corría el año de 1792 .

Sin embargo, es oportuno recordar algunas de las actividades culturales y académicas que realizó en su corta estancia en Quito. Calama, ya desde antes, mostró una apertura a la filosofía moderna; en el plan de estudios que realizó para la Universidad introdujo, recomendando su lectura, las Instituciones filosóficas de Jacquier, obra de la que llevó varios ejemplares. Sin embargo, al parecer, nunca se aceptó esta obra como libro de texto "ni en el Seminario de San Luis ni en el Convictorio de San Fernando, con todo contribuyó no poco a que los profesores de filosofía ampliaran y mejoraran una enseñanza tan importante". ${ }^{2}$

Al parecer, Calama se sintió decepcionado de algunas autoridades eclesiásticas de Quito por no aceptar las ideas de la filosofía moderna, esto dio como resultado su desilusión ante la postura exageradamente tradicional de la mayoría de las autoridades religiosas de dicho país; éste, por demás importante problema, en relación con la educación y actualización filosófica de los jóvenes

2 "Jacquier fue religioso mínimo y dictó filosofía en Roma: en sus Instituciones filosóficas trata de la filosofía experimental, de la astronomía y de las matemáticas con no poco acierto y claridad". Nos advierte el doctor De la Torre Villar que las noticias que nos da sobre la actuación de Calama en Quito están tomadas de su biógrafo y sucesor en el obispado de Quito, el historiador Federico González Suárez, quien "en su soberbia Historia del Ecuador nos dejó páginas magistrales en torno de su antecesor en la mitra quiteña" (E. de la Torre Villar, "Introducción", en J. Pérez Calama, op. cit., p. 17). Los datos que siguen, advierte De la Torre Villar, están tomados del volumen quinto y del volumen séptimo de la obra citada. 
seminaristas amargó a Calama y quizá fue la causa de las alteraciones en su carácter que llegaban, a veces, a la violencia.

Su biógrafo afirma:

Ningún obispo de Quito ha sido tan afanado por la instrucción del clero como el señor Calama. Apenas llegó a esta ciudad cuando estableció conferencias a las cuales asistía él mismo en persona y animaba a los sacerdotes a estudiar, deseando que todos amaran las ciencias y se dedicaran al cultivo de ellas, y los estimulaba proponiendo temas sobre los cuales quería que escribieran, y ofreciéndoles premios a los escritores. $^{3}$

Las propuestas de Calama no tuvieron el éxito que él esperaba, esto, como hemos dicho, afectó su carácter, por demás sensible, así como su conducta, ya que decidió abandonar la residencia de la sede episcopal y se trasladó a vivir en un convento de dominicos, donde residió hasta el día que salió de Quito. Lo anterior nos conduce a suponer que tuvo bastantes problemas al interior de la mitra, precisamente por su franca tendencia a la modernidad.

Su interés por la educación de los clérigos, así como en superar las propuestas y metodología de la teología escolástica tradicional y de introducir la teología positiva tampoco tuvo el éxito esperado.

Por otra parte, es necesario, por su importancia, mencionar la relación que mantuvo Calama con los ilustrados quiteños y peruanos. Según afirman su biógrafo y el doctor Ernesto de la Torre Villar, Calama se comunicó y tuvo trato con Francisco Javier de Santa Cruz y Espejo (1747-1795), ilustrado e introductor del pensamiento moderno en Ecuador. ${ }^{4}$

Espejo fundó la "Sociedad patriótica de amigos del país" en 1791, año en el que arribó Calama a Quito. Como órgano de dicha sociedad fundó el periódico Primicias de la Cultura de Quito, el primer número salió el 5 de enero de 1792. El fin de dicha sociedad era estudiar y resolver los muchos problemas que aquejaban a Ecuador; entre ellos, el principal era la pobreza y unido a él la necesidad de fomentar la ciencia y, en general, la educación. Calama simpatizó y apoyó las ideas de Espejo, así como tuvo la inquietud de establecer comunicación con el grupo criollo de ilustrados de Perú, comunicación que no

${ }^{3}$ E. de la Torre Villar, "Introducción”, en J. Pérez Calama, op. cit., p. 16.

${ }^{4}$ Sobre Francisco Javier de Santa Cruz y Espejo puede consultarse mi libro Eclécticos portugueses del siglo XVIII y algunas de sus influencias en América. México, El Colegio de México, 1958, p. 196 [1a. reimp. México, unAm, Colegio de Filosofía, Seminario de Filosofía Moderna, 1979]. En dichas páginas trato ampliamente la entusiasta acogida que dio Espejo a la teología positiva. 
tardó en lograr; les escribió felicitándoles por su periódico el Mercurio Peruano y les remitió, para su publicación, algunos escritos de los que era autor.

Ernesto de la Torre Villar cita una carta de Pérez Calama publicada en el Mercurio Peruano el 23 de junio de 1791, "en la cual alaba y expresa su satisfacción por la presencia en Santa Fe de Bogotá y en Lima de dos virreyes ilustrados y de la aparición del Papel Periódico de Santa Fe y del Mercurio Peruano". 5 Todo ello nos muestra, sorpresivamente, a un Calama admirador de la política ilustrada de Carlos III, sobre todo en relación con la educación, que podría definirse como "modernidad ilustrada"; viene a confirmar lo anterior las críticas de Calama a los jesuitas, al "laxismo" y al "probabilismo". 6

Calama cultivó amistad con los ilustrados de Ecuador y de Perú, lo confirma el hecho de que el Mercurio Peruano publicó, en su número del 29 de enero de 1792, el discurso que pronunció Calama "como director de la Sociedad Económica”. En este discurso descubrimos un Pérez Calama interesado, principalmente, en la economía de Ecuador y en los medios para restablecerla. Comienza señalando la "suma pobreza" que existía tanto en las ciudades como en el campo ecuatoriano; advierte la urgencia "del arte de hacer dinero sin escrúpulos de conciencia”, propone fomentar la agricultura, las artes y el comercio, así como la fundación de una casa de moneda, indicando que, sobre todo, debe procurarse "un comercio activo interno y externo". Concluye afirmando la necesidad de reestructurar "nuestra moribunda patria".

Como puede advertirse, si Calama sufrió en Quito un rechazo a sus ideas innovadoras de parte de la escolástica decadente, también tuvo una amistosa y entusiasta acogida de los ilustrados, y aquí surge la pregunta clave: ¿por qué motivos, todavía no claros, Calama decidió abandonar presurosamente el obispado de Quito y regresar a México? Ni su biógrafo ni el doctor De la Torre Villar se lo platean ni resuelven, apenas su biógrafo pasa a referirse al carácter inestable de Calama. Sin embargo, me permito no aceptar ese supuesto motivo, más bien me inclino a considerar otros, que también someto a duda, ¿temía quizá Calama una peligrosa reacción del escolasticismo decadente quiteño?, ¿descubrió que los ilustrados quiteños y peruanos en sus propuestas innovadoras tenían

${ }^{5}$ E. de la Torre Villar, "Introducción”, en J. Pérez Calama, op. cit., p. 38.

${ }^{6}$ Tanto Pérez Calama como Espejo tuvieron influencia, en este tema y en otros, del filósofo portugués Luis Antonio Verney. Recordemos que, unida a estas críticas, se encuentran en muchos de los escritos de Calama palabras de desprecio y crítica a la escolástica decadente; refiriéndose a los periódicos citados afirma: "no dudo que su lectura deshollinará muchas chimeneas de entendimientos aerostáticos y que a los jóvenes les preservará de embadurnarse con las especies ridículas y gritonas del ente de razón. Cada día lloro más el tiempo que me consumió la educación bárbara que me franquearon los ergotistas hasta la edad de veinte y un años. La epidemia era universal entonces; y lo peor es, que todavía sigue en España y en Indias” (Idem). 
también la idea de una independencia frente a España y esto causó temor y descontento en Calama y, por lo mismo, decidió su apresurado regreso?

El verdadero iniciador, en el Colegio de San Nicolás, de la "revolución intelectual y académica" fue Pérez Calama. ¿En qué consistió dicha "revolución"? La respuesta es precisa y concreta: $a$ ) se proponía y planteaba la necesidad de abandonar la teología especulativa escolástica tradicional y su método de estudio y exposición, para dar paso y seguir la metodología y las propuestas de la teología positiva histórica $;^{7}$ b) lo que implicaba abandonar la línea tomista para abrirse a la escuela agustinense y realizar una importante tarea de carácter innovador consistente en seguir a los teólogos de dicha escuela en todo lo referente al estudio, metodología y enseñanza de la teología; $c$ ) consecuencia de lo anterior, y esto era quizá lo más importante y comprometido, no seguir los programas de estudio y enseñanza impuestos por España y aceptados por la Real y Pontificia Universidad de México. Éste era el punto de rebeldía y, por lo mismo, el más peligroso, así como el más importante para el estudio que realizo. ${ }^{8}$

Debemos recordar que ya desde finales de la Edad Media, precisamente en la corriente nominalista, y más tarde en la escuela agustinense, se presenta un marcado interés por una renovación en cuanto al estudio y metodología en el discurso teológico. Entre los innovadores, nominales o modernos en el espacio teológico y filosófico, es necesario tener presente la figura de Juan Gerson o Juan Charlyer de Gerson, fallecido en la ciudad de Lyon en 1429. ${ }^{9}$ Gerson no siguió todas las propuestas filosóficas de los nominales, pero sí aceptó e insistió en una reforma al estudio y enseñanza de la teología, inclinándose a establecer una conciliación entre la nueva visión teológica y la teología escolástica tradicional. Las propuestas y lineamientos más significativos de dicha reforma eran, principalmente, la necesidad de que la teología se alimentara en la Biblia, esto es, que sus principales bases fueran el Antiguo y Nuevo Testamento, la tradición apostólica, la patrística, los testimonios conciliares y las diferentes ciencias que debían ser auxiliares de la problemática teológica, tales como la historia y la geografía, principalmente.

${ }^{7}$ Según Ricardo G. Villoslada, S. I., fue el teólogo John Maior (1469-1550) el primero en usar la designación de teología positiva oponiéndola a la teológica escolástica especulativa tradicional. R. García Villoslada, La Universidad de París durante los estudios de Francisco de Vitoria. 1507-1522. Roma, Universidad Gregoriana, 1938, p. 128.

${ }^{8}$ Es oportuno recordar que fray Ramón Casaus, O. P., maestro de la Real y Pontificia Universidad de México, escribió el Anti Hidalgo, así como la carta que José Blas Abadiano y Jasso, rector de la misma Universidad, le dirigió a Hidalgo.

${ }^{9}$ Gerson fue alumno del también nominalista Pedro D'Ailly y profesor y canciller de la Universidad de París. 
Más tarde en París, en el siglo XVI, John Maior o Juan Maior, quien fue uno de los principales y más brillantes teólogos de la época, rector y maestro del Colegio de Monteagudo, nominalista moderado, se convierte en uno de los defensores y principales representantes de la corriente teológica innovadora. Vayamos a las palabras de Maior, quien en su Epístola, libro 1, de las Sentencias de Pedro Lombardo, comenta ampliamente: "la mayor parte (de la gente) [...] con el ceño fruncido se burla evidentemente de los teólogos y la causa de esto es que encuentra más veces citado a Aristóteles en su conocida Física y en su Metafísica con su comentador, que a los doctores de la Iglesia".

Y en el mismo Comentario a las Sentencias, vol. I, libro 4, folio 1, insiste:

[...] no es malo introducir la filosofía y las demás ciencias sin las cuales la teología no puede ser entendida [...] es laudable introducir las ciencias extrañas a la teología, no sólo las necesarias sino las conducentes a su decoro. Se prueba: los hechos de los apóstoles, padres venerables y los fundamentos de la doctrina teológica deben ser imitados; es así que el beato Gerónimo, Agustín y otros doctores introdujeron (en la teología) los escritos de Marco Tulio, Virgilio, de los filósofos y de los poetas.

Y deseando guardar una posición moderada añade:

En principio no apruebo la opinión de aquellos que dicen que los teólogos deben usar la autoridad de la Biblia, porque si es así el que está fuera de la Universidad sería teólogo, de aceptar esto, el estudio en París no tendría la célebre fama que posee [...] por otra parte no apruebo a éstos que exageradamente introducen en la teología cuestiones inútiles en cuanto relacionadas a las artes (filosofía) porque impugnan extensamente opiniones frívolas con abundancia de palabras. ${ }^{10}$

Es evidente la oposición, por demás interesante, en el discurso teológico entre la corriente nominalista y la tomista, oposición que, como sabemos, dio lugar a muchos problemas dentro de la filosofía y de la teología.

Este interés por la teología positiva histórica continuó en Europa en el siglo XVII. Los estudios histórico-positivos adquirieron gran importancia en el pensamiento de la mayoría de los teólogos, abandonando, como resultado,

${ }^{10} \mathrm{Al}$ parecer fue sor Juana la primera que introdujo en México la tendencia hacia la teología positiva histórica, precisamente en la Carta atenagórica o Crisis sobre un sermón, año 1690, y en la Respuesta a la muy ilustre sor Filotea de la Cruz, año 1691. 
la teología sistemática y especulativa. ${ }^{11}$ Los estudios sobre teología histórica se desarrollaron notablemente en Francia, así como en Italia y en Alemania.

Aparece otra nueva escuela llamada de los agustinianos, constituida por varios teólogos agustinos y por algunos profesores de la Universidad de Lovaina que siguen, en la interpretación de san Agustín, un camino intermedio entre el de los antiguos escolásticos y el de la herejía jansenista. ${ }^{12}$

Martin Grabmann advierte que "la llamada escuela de los agustinenses, que nació también en esta época (siglo XVII y XVIII), se acercó más en principio a las doctrinas de Gregorio de Rimini [...] llegando en ocasiones a aproximarse demasiado a las teorías jansenistas". ${ }^{13}$ Asimismo, señala Grabmann, que "los españoles prefirieron continuar con la teología especulativa que cada vez decayó más por el afán desmedido a sutilezas sobre cuestiones de poco o de ningún interés". ${ }^{14}$ Esto ocurría, lamentablemente, en España a mediados del siglo XVII y XVIII. En conclusión, en el proyecto innovador dentro de la teología católica confluían la línea nominal y la agustina.

En páginas siguientes el lector podrá comprobar que Pérez Calama se proclama fiel seguidor de los agustinenses en la reforma teológica, aceptándola y llevándola a cabo en el Seminario Nicolaíta. Cita con gran admiración al teólogo agustino italiano Berti (†1766), a Cristiano Lupo (†1681), también teólogo de la Orden de San Agustín, que enseñó en Lovaina, así como lanza sus críticas contra Gonet $(\dagger 1681)$ por sus innumerable sutilezas, seguidor de la escuela tomista, aconsejando, por lo mismo, que su libro debía retirarse de las

${ }^{11}$ Especulación, del latín speculatio, originalmente observar o espiar, examen o estudio teórico, en este sentido existe cierta analogía entre especular y lucubratio o lucubrar; lucubración es el acto llevado a cabo a la luz de una vela. Santo Tomás de Aquino entendió especulación como teoría; en los modernos se entiende por especulación algo alejado de la práctica. Sin embargo, fue Boecio el primero que le dio un sentido filosófico, como contemplación. Gregorio Magno habló de la Torre speculationis o Torre de la contemplación.

${ }^{12}$ Martin Grabmann, Historia de la teología católica. Madrid, Espasa-Calpe, 1940, p. 247.

${ }^{13}$ Ibid., p. 253. Gregorio de Rimini (†1358), siguió la posición nominalista; fue miembro de la Orden de los Ermitaños de San Agustín, llegó a ser general de ella. Estudió en París, fue profesor en las Universidades de Bolonia y Padua. Comentó las Sentencias de Pedro Lombardo. Algunos autores afirman que, en cierto modo, fue un precursor de Lutero.

En relación con "las teoría jansenistas", mencionadas por Martin Grabmann, es necesario recordar a Cornelius Janssens o Jansenio (1585-1638), que impartió clases en Lovaina y fue obispo de Ypres. Sin embargo, en su libro titulado Augustinus, en el enfoque de algunos temas agustinianos, entre los que pueden nombrarse el de la gracia y el del pecado original, se opone a lo dicho por el magisterio de la Iglesia, por ello fue considerado hereje.

${ }^{14}$ M. Grabmann, op. cit., p. 247. 
cátedras de teología y, en todo caso, acudir directamente a la Suma de Tomás de Aquino.

Esta corriente de renovación teológica, principalmente realizada por la orden agustinense, fue un movimiento muy valioso a pesar de la opinión de algunos que la relacionaron con la herejía jansenista. Sin embargo, vino a dar, indudablemente, un vigor a la teología, una renovación espiritual, dando lugar a una cercanía con el hombre, esto es, a un proyecto cristiano más profundamente vívido.

Pasemos a la obra de Pérez Calama, Política christiana. Para toda clase de personas, extractada de los documentos y avisos de san Gregorio el Magno, en la tercera parte de su pastoral. ${ }^{15}$ Dicha obra fue publicada en 1782 en la Nueva Ciudad de la Asunción, Guatemala: "La da a luz don Francisco Antonio Fernández de Llar, capellán de la Real Audiencia de Guatemala”. En relación con estos datos surgen varias preguntas, todavía sin clara y precisa respuesta. ¿Por qué Calama publicó su obra en Guatemala?, ¿por temor o por cierto cuidado con relación a cómo podría ser recibida en México?, ¿Francisco Antonio Fernández de Llar guardaba una posición similar a la de Calama en relación con la teología positiva histórica?, ¿fue Francisco Antonio Fernández el amigo a quien Calama dirigió la carta que él mismo menciona en su Política christiana? Por lo pronto atendamos a lo que nos dice el propio autor con relación al título de ella: "Y pues política es lo mismo que método o estilo, que cada cual en palabras y obras debe observar y esta obrilla propone en nuestro idioma castellano, el que para cada clase de personas prescribe san Gregorio, me pareció que no le desdecía el título que lleva al frente". ${ }^{16}$

La obra presenta las censuras, licencias y dictámenes necesarios que se acostumbraban en la época, así como dedicatorias y un prólogo del autor acompañado de un discurso preliminar en los que, primordialmente, enfoca cuáles deben ser las palabras propias para dirigirse a diferentes clases de personas. De acuerdo con lo anterior, se presenta dividida en XV avisos, por ejemplo, el aviso I lleva este título: "De los jóvenes y ancianos"; aviso II: "Pobres y ricos"; aviso III: "Alegres y tristes..."; aviso VIII: "Orgullosos y presumidos", etcétera. Al final del aviso VI reproduce la carta que sobre la verdadera teología escribió a un amigo. Con ironía, Calama dedica este aviso vi a los sabios o estúpidos o de corto entendimiento, aconsejando a los primeros "no engreírse y ceder a la razón", añadiendo una opinión al parecer de san Pablo a

${ }^{15}$ Política de polis, ciudad; politicus, política, politicum lo referente al gobierno. Podría entenderse el título de la obra como el gobierno de la cristiandad. Quizá Calama tenía en mente el título que Gerson dio a una de sus principales obras: Política eclesiástica.

${ }^{16}$ J. Pérez Calama, op. cit. Las cursivas son mías. 
los hebreos: "todo aquello que ya va en decadencia y envejeciéndose, está mui cerca de su exterminio y aniquilamiento". ${ }^{17}$ Obviamente, Calama dirigía este texto a los seguidores y defensores de la teología escolástica tradicional especulativa y se permite aconsejar, en general, a los teólogos la necesidad de tener en cuenta y sujetarse a los lugares teológicos, planteados por Melchor Cano, ${ }^{18}$ así se evitarían "las questiones ridículas, que de teología no tienen más que el nombre" y pasando a afirmar que los españoles Cano y Villavicencio "son la regla y norte de los sabios franceses e italianos"; cita entre éstos a Goti, Berti, al francés Droubet de Resacramentario, a Cristiano Lupo, añadiendo que en ellos se encuentra "el fundamental método de indagar la verdad en el recto uso del ergo escolástico. Seguir otro camino es hacerse puros sofistas, que sólo en lo mucho que hablan se distinguen de los de poco talento". ${ }^{19}$

Me permito presentar al lector las palabras de Calama, ya que, aunque en párrafos un poco extensos, nos dan una idea clara de su posición dentro de la teología:

Sabe Vm. por nuestras conferencias reiteradas, quanto me glorio de ser fiel discípulo de mi angélico doctor santo Tomás; mas no por esto me he atrevido, ni atreveré a imponer nota o censura, que en la teología se merece mi angélico maestro, se funda en ser fidelísimo discípulo del gran padre san Agustín [...] concluyo esta mi carta ratificando a Vm. lo que varias vezes me ha oído: es a saber: que en todo y por todo anelo seguir, y abrazar la doctrina de san Agustín, pues como dijo Volusiano: lo que falta en tan gran doctor también falta en la Ley de Dios. Por este espíritu de conformidad, y filial imitación, que se manifiesta en las obras teológicas de el erudito augustiniano Berti, le soy y le seré de por vida mui su apacionado [...] Ruego también a todos los teólogos cursantes que lean y relean las eruditas cartas del sabio Ganganeli. ${ }^{20}$ Concluye joxala! que yo hubiera sido

${ }^{17}$ Se ha conservado la ortografía del autor.

${ }^{18}$ Lugares teológicos: fuentes de la ciencia teológica que debe consultar el teólogo. Melchor Cano cita diez fuentes o lugares: escritura, tradición apostólica, autoridad de la Iglesia, concilios, magisterio del papa, testigos de la tradición (los santos y los padres), interpretación del dato, revelación, razón natural, autoridad de filósofos y juristas y la historia (Miguel Ángel Sobrino Ordoñez, Incienso, imágenes, diezmos y otras cosas. Nociones fundamentales de ética, dogma, legislación y ritual de la Iglesia católica colonial en América Latina. Obra de próxima publicación).

${ }^{19}$ Se ha respetado la ortografía del autor.

${ }^{20}$ Clemente XIV al cardenal Qurini, sobre el verdadero método de estudiar la teología. Es la 49 y está en el tomo I, fol. 233. 
conducido y enseñado con arreglo a principios tan sólidos. Mas el humo del ergo vocinglero me cegó. ${ }^{21}$

Pérez Calama no fue simplemente un teólogo innovador, sino que a través de su lectura puede advertirse el amplio conocimiento que tenía del problema teológico existente en España, así como en el resto de Europa y en México. Indudablemente mantuvo una posición de rebeldía ante la teología tradicional escolástica, posición por demás comprometida por la separación que esto implicaba con la línea tomista y la cercanía de algunos agustinos con la herejía jansenista. Calama es preciso en sus afirmaciones y guarda un sabio equilibrio, lo mismo sucederá con Hidalgo en su Disertación, al referirse a Tomás de Aquino; sin embargo, plantea también, muy moderadamente, su decisión de seguir al agustino Berti. Por otra parte, basándome en una carta firmada por Calama y por el doctor Juan Antonio de Tapia que lleva por título Decreto sobre provisiones de cátedras en el Seminario Tridentino de Valladolid de Michoacán e introducción de autores modernos (1784), ${ }^{22}$ puede afirmarse que Calama tenía muy claro el programa de enseñanza de teología que debía impartirse en el Seminario - que no era otro sino el de la escuela agustinense-, así como los doctores y bachilleres que tendrían a su cargo las cátedras correspondientes de teología. Pérez Calama tenía un grupo de seguidores que por lo mismo aceptaban sus ideas innovadoras dentro de la teología. ${ }^{23}$

Mostró también un interés por la filosofía moderna. En la carta, a la que acabo de referirme, después de advertir que el bachiller don José María Pisa impartiría filosofía, indicando, concretamente Calama, en Un discurso histórico-crítico sobre la sólida filosofía, afirma que debe dársele un mayor estudio "en lo intensivo y extensivo a la filosofia moral". Encontramos dos advertencias muy interesantes, primero la de realizar "un discurso histórico-crítico sobre la sólida filosofía"; la segunda, la insistencia en el estudio de la filosofía moral, esto es, de la ética. En relación con lo primero, se advierte siempre en Calama un profundo sentido crítico, ya sea sobre la teología o sobre el discurso filosófico; en relación con lo segundo, era común entre nuestros filósofos anteriores y posteriores a Calama la insistencia en la enseñanza de la ética, lo cual indica la preocupación por realizar un estudio sobre las opiniones de los antiguos y modernos en relación con una materia que juzgaban importante; un

${ }^{21}$ El subrayado es mío. En todas las citas se ha respetado la ortografía del autor.

${ }^{22}$ Dicha carta y otras también muy interesantes aparecen en la edición ya citada de la obra de José Pérez Calama.

${ }^{23}$ Esto sería muy interesante de confirmar o negar a través de la "Colección de documentos relativos al doctor José Pérez Calama". Creo que es una investigación necesaria por hacer. 
ejemplo de esto es el oratoriano Juan Benito Díaz de Gamarra y Dávalos, contemporáneo de Calama. ${ }^{24}$

Entre los filósofos modernos que deben seguirse, Calama cita a Feijoo, a Piquer y al portugués Luis Antonio Verney:

Hallarán (los maestros y alumnos del seminario) la invención más profunda y sólida en los varios discursos que sobre este punto dejó escritos el ilustrísimo Feijoo, y con especialidad les encargamos lean los cuatro primeros del tomo octavo y el 11, 12 y 13 del tomo séptimo; en el índice de la filosofía moral por Codorniu; en los discursos preliminares de la lógica, ética del sabio Piquer; sin que omitan la lectura del crítico Barbadiño sobre este punto insinuado y el libro de oro que se dice: Método de estudios sacados de san Agustín por los apatistas de Verona, el que en dos días, a más tardar, se puede leer. ${ }^{25}$

Aconseja también que se vea a Cicerón, "en una oración crítica-histórica sobre sus obras".

Me inclino a pensar que en estas páginas ha quedado demostrada la posición de Calama en relación con el problema teológico tan discutido en su momento. Calama es el primero que plantea la rebeldía intelectual y académica en el Seminario nicolaíta. Este movimiento intelectual y académico de renovación teológica y filosófica que realiza Calama platea una innovación revolucionaria en su contexto colonial mexicano, cuya premisa principal era aceptar lo ordenado por la metrópoli. Es oportuno recordar lo dicho por el marqués de Croix, caballero de la Orden de Calatrava, gobernador y capitán

${ }^{24}$ Afirma Gamarra "A nosotros nos pareció conveniente dedicar este esfuerzo a tan hermosa disciplina descuidada hasta ahora en las escuelas de nuestra América no se por qué, con grandísimo perjuicio de la juventud y doctrina de la filosofía. Más útiles son estas cosas que disputar acremente sobre el ente de razón, sobre la conexión de Dios con la posibilidad o imposibilidad de los posibles, y sobre otros trescientos temas" Juan Benito Díaz de Gamarra y Dávalos, Elementos de filosofía moderna, t. I. Present., trad. y notas de Bernabé Navarro. México, unAM, Centro de Estudios Filosóficos, 1963).

${ }^{25}$ Fray Benito Gerónimo Feijoo (1676-1764). Piquer, al parecer, fue un ecléctico español del siglo XVIII. Luis Antonio Verney, conocido también por el seudónimo de el Barbadiño (1713-1792), fue el introductor de la filosofía moderna en Portugal. Verney influyó considerablemente en los países latinoamericanos, concretamente en México, Ecuador y Cuba. En cuanto a Antonio Codorniu, jesuita contemporáneo a Verney, es necesario aclarar que se opuso al filósofo portugués y que escribió una obra titulada Desagravio de los autores y facultades que ofende el Barbadiño en su obra Verdadero método de estudiar. Barcelona, 1764. Basándonos en esto podría parecer en Calama una contradicción cuando alaba a el Barbadiño y a Codorniu por igual, sin embargo, Calama se refiere a la filosofía moral de Codorniu, no a la crítica que este autor realizó a Verney. 
general del reino de Nueva España, presidente de la Real Audiencia, "pues de una vez para lo venidero deben saber los súbditos del gran monarca que ocupa el trono de España que nacieron para callar y obedecer y no para discutir ni opinar en los asuntos de gobierno". ${ }^{26}$

Estas palabras fueron pronunciadas pocos años antes de las propuestas innovadoras y rebeldes de Calama y de Hidalgo. Pueden, por lo mismo, y con toda razón, ser calificadas de rebeldía intelectual y académica las nuevas ideas sobre los estudios teológicos y filosóficos impuestas en el Seminario Nicolaíta. En Hidalgo, como veremos, se agudiza más el tema. Es así como la rebeldía en lo intelectual y académico preparaba el camino a la rebeldía en lo político. La independencia académica se anticipaba y abría el camino a la independencia política. Éste es el proceso concreto que puede advertirse en la Disertación de Miguel Hidalgo y Costilla.

Como ya se ha dicho, la Disertación la presenta Hidalgo en 1784 en el Concurso convocado por Pérez Calama, obteniendo el premio ofrecido. ${ }^{27}$

Calama le dirige una carta a Hidalgo en la que lo felicita con entusiasmo otorgándole los calificativos de "hormiga trabajadora de Minerva" y "abeja industriosa que sabe chupar y sacar de las flores la más delicada miel":

Con el mayor júbilo de mi corazón preveo que llegará a ser Vmd. luz puesta en el candelero o ciudad colocada sobre un monte. Veo que es Vmd. un joven que cual gigante sobrepuja a muchos ancianos que se llaman doctores y grandes theólogos, pero que en realidad son unos meros ergotistas cuyos discursos o nociones son telas de araña, o como dijo el verdadero theólogo Melchor Cano, son cañas débiles con que los muchachos forman juguetes. ${ }^{28}$

Lejos estaba Calama de imaginar que veintiséis años después ese joven teólogo encabezaría un movimiento armado de independencia, que moriría trágicamente y habría de convertirse en héroe nacional.

Calama, como buen maestro, no pierde la oportunidad para hacer a Hidalgo dos recomendaciones: la primera, que en la Disertación debió de presentar en castellano y no en latín las páginas que reproduce del sabio Gerson, con el fin de que todos pudieran comprender con facilidad lo dicho por el teólogo francés; la segunda, que lea y estudie las Instituciones catho-

${ }^{26}$ Boletín de la Biblioteca Nacional de México, núms. 57 y 58, marzo 31 y abril 30 de 1909. Documentos históricos "bando de expulsión de los jesuitas".

${ }^{27}$ Hidalgo escribió dos Disertaciones, una en latín y otra en castellano; la primera, la que presentó en idioma latino, se ha perdido.

${ }^{28}$ Luis Castillo Ledón, Hidalgo. La vida del héroe. México, 1948, vol. I., cap. X, p. 36. 
licas de Francisco Amato Pouguet, regla y pauta para todos los profesores de teología.

Por otra parte, se advierte en esta carta el entusiasmo del maestro ante el discípulo que ha aceptado y sigue los caminos, señalados por el primero, de renovación teológica y filosófica. No olvidemos que fue Calama el primero en plantear y llevar a cabo en el Seminario nicolaíta esta actualización. ${ }^{29}$

Por otra parte, Castillo Ledón aporta datos interesantes en relación con las actividades de Hidalgo como teólogo; nos informa que el día 15 de julio de 1785 se celebraron en el Colegio dos actos:

[...] presididos por el presbítero Miguel Hidalgo, nombrado ya propietario de la cátedra de teología, los alumnos sustentantes, bachilleres Felipe Antonio Texeda y Juan Antonio de Salvador, respondieron según las doctrinas del padre Serry, y demostraron conocer al padre Graveson, haciendo una hábil defensa de las Prelecciones del primero y de la Historia eclesiástica del segundo. Estos dos actos literarios, decía la Gaceta de México de 9 de agosto del propio año, se hacen más dignos de la noticia de todos, por el acierto que en su defensa tuvieron los dos expresados jóvenes, pues el primero satisfizo plenamente las réplicas que le objetaron, concilió con claridad las antilogías que le propusieron, haciendo ver que sólo eran aparentes, y últimamente vindicó al autor de la infame calumnia de jansenista, con que algunos han querido denigrar sus obras. El segundo igualmente res-

${ }^{29}$ Al final de la transcripción de esta carta hay un comentario que puede dar lugar a confusión y error. Con relación a ello, y en primer lugar, es necesario advertir que dicha carta y otras de Pérez Calama aparecen en la edición consultada de Política christiana reunidas bajo el título de "Apéndice documental"; en segundo lugar, todas las cartas, excepto la que Calama felicita a Hidalgo, están tomadas de la "Colección de documentos relativos al doctor José Pérez Calama”, 1776-1785, ff. 17-18; en tercer lugar, la carta de la felicitación lleva a pie de página la siguiente aclaración: texto tomado de Luis Castillo Ledón, Hidalgo. La vida del héroe. México, 1948, vol. I., cap. X, pp. 36-37; en cuarto lugar, Castillo Ledón comentando la carta en cuestión, afirma lo siguiente: "Como Miguel planteaba todo un serio problema, digno de ser estudiado y de procurar su solución, no cabe duda que las opiniones que emitía y los argumentos en que fundaba éstas, decidieron al señor Pérez Calama, que como jefe del cabildo intervenía en la dirección del Colegio, a influir para que se hiciera una reforma en los estudios de teología, cambiando el texto de Gonet por otro más de acuerdo con las exigencias señaladas por el autor de la Disertación" (L. Castillo Ledón, op. cit., p. 37). Aclaro, basándome en fechas y testimonios que en páginas anteriores se han dado a conocer al lector: Calama no se decidió a seguir la innovación teológica después de leer a Hidalgo, sino todo lo contrario, fue Hidalgo después de oír y leer a Calama el que tomó partido por la línea agustiniana de renovación teológica. 
pondió con solidez los argumentos que se le pusieron y según el orden con que le preguntaron, y refirió con mucha expedición los puntos de historia, del autor. ${ }^{30}$

Como puede advertirse, este comentario de la Gaceta de México es sumamente importante porque, en cierto modo, se daban a conocer las actividades que en materia teológica se realizaban en el Colegio nicolaíta. Continua Castillo Ledón: "En virtud de esto merecieron el universal aplauso del concurso bastante numeroso, y que el Ilm. V. Sr. deán y cabildo (como patrono del Colegio) les premiase con dos cátedras de filosofía y de gramática que estaban vacantes".31

La línea de renovación teológica planteada, en primer lugar, por Pérez Calama y más tarde por Hidalgo, se mantenía y se reconocía. ¿Hasta cuándo siguió esta postura innovadora y un tanto rebelde en el interior del Seminario Tridentino de Valladolid y del Colegio de San Nicolás?, ¿cuántos fueron los fieles a ella? Al parecer comienza con la publicación de la obra citada de Calama y con su intervención y magisterio, pero ¿̇hasta cuándo perduraron, en dichas instituciones, las importantes innovaciones de Calama en la teología y su método de enseñanza? Son preguntas claves que quizá algún día podamos responder.

Antes de pasar al análisis del texto de la Disertación es necesario recordar el título completo de ella, título que otro autor de la época había dado a su obra. El autor al que me refiero, ya citado en páginas anteriores, es el filósofo portugués Luis Antonio Verney, conocido también por el seudónimo de el Barbadiño. Verney tituló su principal obra, que tanto influyó en México y en otros países de América Latina, Verdadero método de estudiar para ser útil a la república y a la Iglesia, publicado en Madrid en $1760 .{ }^{32}$ En esta obra somete a crítica el enfoque tradicional y anticuado que se daba en Portugal y

${ }^{30}$ L. Castillo Ledón, op. cit., pp. 37-38.

${ }^{31}$ Ibid., p. 38.

${ }^{32}$ La Disertación consultada, que por lo mismo ha servido como referencia para este estudio, es la que aparece en Gabriel Méndez Plancarte, Hidalgo, reformador intelectual y libertador de los esclavos. Morelia, Universidad Michoacana de San Nicolás de Hidalgo, Centro de Estudios sobre la Cultura Nicolaíta, 1982. (Biblioteca de nicolaítas notables, 12)

El título completo de la Disertación es Disertación sobre el verdadero método de estudiar teología escolástica. Compuesto por el Br. Don Miguel Hidalgo Costilla, Catedrático que fue de latinidad y artes en el Real y más antiguo Colegio de San Nicolás Obispo, de esta ciudad de Valladolid, Colegial de oposición y catedrático de Prima Sangrada Teología en el mismo Colegio. Puede advertirse la similitud del título entre uno y otro texto, esto es, entre el de Verney y el de Hidalgo. 
en España a la literatura, a la oratoria sagrada, a la ética, etcétera; así como a la teología. En relación con esta última se presenta como fiel y entusiasta partidario y servidor de la escuela agustinense, y por lo mismo de la teología histórica positiva, critica a la teología especulativa y al método de investigación y exposición empleado en ella, insiste en la necesidad de la crítica histórica, no sólo en teología sino en todos los estudios.

Hidalgo cita dos veces en su Disertación a Verney. La primera en relación con el doble sentido que tienen las palabras teología y escolástica:

\section{[...] dice el abate Verney en su Verdadero método de estudiar...: el} primero es: teología metódica acomodado (a) al uso de la escuela con argumentos y respuestas por el modo dialéctico; y en este sentido sólo se distingue accidentalmente de la positiva. Otro sentido es: teología fundada en las opiniones de Aristóteles, digo de las formas substanciales, introduciendo mil cuestiones de posibles inútiles [...] empleando todo el tiempo en sofismas metafísicos. Esta es la escolástica común y en este sentido es totalmente distinta a la positiva y todos los mejores teólogos la condenan con el Cardenal Gotty.

Hasta aquí la cita de Verney que transcribe Hidalgo con base en la cual se advierte no sólo la influencia de Verney sino también la de Pérez Calama.

La segunda vez que Hidalgo cita a Verney es a propósito de la crítica que el propio Hidalgo realiza de Gonet, concretamente del Compendio; con el fin de darle un mayor peso a sus palabras advierte que el Barbadiño juzga como inútiles muchas de las cuestiones tratadas por Gonet.

Hidalgo comienza su Disertación con unas palabras de Cicerón, citadas y comentadas a su vez por el teólogo Graveson: "Es una perversa obstinación, decía Tulio, mantenerse con bellotas después de descubrir las frutas”. Las bellotas representan a la teología especulativa, las frutas a la teología positiva histórica: "Olvidadas ya aquellas escolásticas sutilezas que sólo servían de pervertir el buen gusto y perder el tiempo, se ha introducido un nuevo método de tratar las cuestiones, metódico sí, pero con arreglo a las Sangradas Letras, a la tradición, a la doctrina de los padres, amenizándolas con la historia y adornándolas con todo género de erudición”.

Es interesante advertir cómo Hidalgo, en su afán de criticar la presencia de la filosofía aristotélica en la teología especulativa, se refiere y denuncia "el abuso de filosofar en las cosas divinas según los principios aristotélicos y reducir nuestra fe a las frívolas reglas de su dialéctica”, lo que dio lugar, según Hidalgo, a que en el año de 1240 circularan varios escritos anónimos que "procuraban oscurecer las verdades de nuestra religión". Cita al obispo de París Esteban Templier (sic) -Esteban Tempier- que años después condenó 
varias proposiciones que "los teólogos de París, fundados en los principios aristotélicos, afeaban y corrompían a la verdadera teología". ${ }^{33}$

Hidalgo se refiere a Juan Gerson, concretamente como él mismo nos informa, a la carta que Gerson escribió "a cierto prelado" y a continuación presenta una extensa cita del teólogo francés, cita que por lo significativo de su contenido me permito trascribir:

Reverendo padre: parece ser necesaria bajo vuestra corrección y la de nuestros maestros en la Facultad de Teología, la reforma de las siguientes cosas, entre otras: Primero, no sean tan comúnmente tratadas doctrinas inútiles, sin fruto y sin solidez, pues que por ellas se abandonan las necesarias y útiles para la salvación: ignoran lo necesario porque se dedican a aprender lo fútil, dijo Séneca. Segundo: por ellas se engañan los estudiantes, pues piensan que son principalmente teólogos quienes a tales cosas se dedican con desprecio de la Biblia y de los doctores sagrados. Tercero: por ellas (las doctrinas inútiles) son alterados los términos usados por los Santos Padres, contra aquello de Agustín: A nosotros nos está permitido hablar hasta cierto límite, etc., y no se produce corrupción más rápida de ciencia alguna que por medio de esta, etc. Cuarto: por ellas los teólogos son la burla de otras facultades, tanto que se les tilda de fanáticos y se dice de ellos que nada saben de la verdad sólida, ni de las cosas morales ni de la Biblia. Quinto: por ellas se abren múltiples caminos al error. Y, pues hablan y forjan para sí términos que otros maestros y doctores ni entienden ni se preocupan por entender, prefieren cosas increíbles y absurdas en extremo, que de sus absurdas ficciones dicen seguirse. Sexto: por ellas ni la Iglesia ni la fe obtienen edificación ni en lo interno ni en lo externo. Consta que dan más bien ocasión para que se crea que Dios no es del todo simple o uno. Séptimo: por ellas los teólogos se escandalizan tanto activa como pasivamente, pues unos llaman a otros rudos, y otros, por su parte, curiosos y fanáticos.

No es importante el hecho de citar a Gerson, sino todo lo que ello implicaba al interior del pensamiento filosófico, religioso y político mexicano. El nominalismo presente, aunque en distintas formas, en el pensamiento mexicano del siglo XVI, continuaba su influencia en el siglo XVIII en relación con la

${ }^{33} \mathrm{Al}$ parecer, Hidalgo se está refiriendo a Amalarico de Bene, siglo XIII. Perteneció a la diócesis de Chartres y fue profesor de lógica y teología en París y a su discípulo David de Dinant o Dinando, ambos plantearon y defendieron tesis panteístas. 
individualidad y libertad del hombre, la autodeterminación frente a postulados que pretendían ser inamovibles.

Con relación a Gerson, afirma Gilson que: "el nominalismo del siglo XIV preparaba una reforma de la teología concebida como una disciplina de la fe, fundada sobre sus propios principios y ligada a la tradición de los padres. Los críticos de la teología escolástica de los siglos XV y XVI no dirían contra ella nada que Gerson no hubiera dicho antes".

Por otra parte, tanto en Pérez Calama como en Hidalgo el agustinismo seguía siendo el eje central de su pensamiento teológico en tanto reformistas frente a la corriente tomista. Como acertadamente afirma Gilbert:

El agustinismo seguía siendo la forma más clásica y más segura del pensamiento recto [...] Podría decirse que, en cierto modo, con Escoto la tensión entre la tradición agustiniana y la tradición tomista toma el aspecto de una oposición entre dos maneras de concebir a Dios [...] Esta tensión zanjada por el nominalismo que muestra por qué hay que retirar de Dios toda verdad accesible a la inteligencia humana, determinará el destino del pensamiento europeo y por lo tanto de la teología. ${ }^{34}$

Como puede advertirse, Hidalgo está siguiendo en su Disertación el pensamiento innovador en teología y filosofía de Pérez Calama, los autores, las propuestas y las críticas son las mismas; sin embargo, se extiende mucho más en la exposición y crítica llegando a afirmaciones, a veces, más decisivas en cuanto a la posición referente a la teología y a la filosofía. Las preguntas que formula evidencian su posición: “¿por qué no les hemos de dar acceso?”, esto es, a los teólogos innovadores y críticos, "¿por qué no vamos nosotros por donde se ha de ir?", ${ }^{35}$ esta última es sumamente significativa por la profunda problemática que contiene; problemática que asevera una posición de rebeldía no sólo intelectual sino vital, que más tarde, como ya hemos afirmado, se proyectará en lo político.

En relación con santo Tomás, Hidalgo, lo mismo que Pérez Calama, mantiene una posición de respeto o más bien de prudencia; las críticas que hace al doctor Angélico son cuidadosas, e incluso al realizarlas, Hidalgo cae en ciertas contradicciones en su interés por justificar la posición de Tomás en su contexto. Indudablemente, Hidalgo y Calama temían la reacción de los escolásticos mexicanos tradicionalistas.

${ }^{34}$ Paul P. Gilbert, Introducción a la teología medieval. Estella, Verbo Divino, 1993, p. 179.

${ }^{35}$ Las cursivas son mías. 
En conclusión, Hidalgo se nos presenta como un fiel seguidor de las propuestas innovadoras señaladas por Calama al interior de la teología. Ambos son los protagonistas de lo que nos hemos permitido calificar de "rebeldía académica" dentro del Seminario y Colegio nicolaítas.

En su Disertación, como hemos dicho, Hidalgo se extiende más que Pérez Calama en la defensa de la teología positiva histórica, esto no quiere decir que Calama no realizara esta defensa, pero sí que Hidalgo abunda más en los ejemplos de autores, como cuando cita a Gerson. Sin embargo, el carácter astuto de Hidalgo lo conduce a plantear el tema de la autoridad de la Iglesia católica y con relación a él se presenta como sumamente respetuoso. Advierte que no es suficiente leer la Biblia

[...] para conocer las verdades que nos ha revelado Dios, es necesario que el sentido de las palabras se concuerde con la doctrina de los santos Padres como manda el Tridentino en la sesión 4a. por estas palabras: "para reprimir a los ingenuos petulantes decreta (el santo sínodo) que nadie fiado en su prudencia en cosas de fe y de costumbres que pertenecen a la edificación de la doctrina cristiana, torciendo la Sagrada Escritura a sus propios sentidos contra el sentido que ha tenido y tiene la santa madre Iglesia, a quien sólo pertenece el juzgar del verdadero sentido e interpretación de las Sagradas Escrituras o también contra el consentimiento unánime de los Padres se atreva a interpretar la misma Sagrada Escritura.

Hidalgo, de acuerdo con lo anterior, no aceptaba al parecer el "libre examen" y citando las palabras del sínodo, aclara su propia posición ante un problema tan importante dentro de la política eclesiástica. Quizá, Hidalgo quería protegerse de las falsas acusaciones, que podían llegarle, de simpatizar con el protestantismo. 